\title{
What Predicts Recovery Orientation in County Departments of Mental Health? A Pilot Study
}

\author{
Timothy T. Brown $\cdot$ Christine B. Mahoney $\cdot$ \\ Neal Adams $\cdot$ Mistique Felton $\cdot$ Candy Pareja
}

Published online: 4 November 2009

(c) The Author(s) 2009. This article is published with open access at Springerlink.com

\begin{abstract}
In this pilot study we examined the determinants of recovery orientation among employees and influential stakeholders in a sample of 12 county departments of mental health in California. A two-level hierarchical linear model with random intercepts was estimated. Analyses show that recovery orientation has a $U$-shaped relationship with the age of staff/influential stakeholders and is negatively related to the difference between the desired level of adhocracy and the current level of adhocracy. Recovery orientation is positively related to the education level of staff/influential stakeholders, satisfying transformational leadership outcomes, and larger mental health budgets per capita. Policy implications are discussed.
\end{abstract}

Keywords Organizational culture - Leadership · Recovery orientation - Mental Health Services Act . Proposition 63

\section{Introduction}

Recovery and recovery orientation are not new; they have been discussed in the mental health field for over 70 years

Earlier versions of this paper were presented at professional meetings. However, the current version has never been presented at a professional meeting.

T. T. Brown $(\bowtie) \cdot$ N. Adams · M. Felton · C. Pareja Petris Center, School of Public Health, University of California at Berkeley, 2150 Shattuck Avenue, Suite 525, Berkeley, CA 94704, USA

e-mail: tbpetris@berkeley.edu

C. B. Mahoney

Nance College of Business Administration, Cleveland State University, Cleveland, OH, USA
(Sowers 2005). International and US longitudinal studies of recovery from major mental illnesses have, over the past 30 years, demonstrated recovery rates of between 49 and 68\% (Harding 2004; Harding et al. 1987). Yet, only within the last 20 years have program administrators and developers become conversant with the notion of recovery from severe mental illnesses (Farkas et al. 2005). Recovery is now recognized as an organizing principle for the transformation of behavioral health services. The recommendations of the President's New Freedom Commission report (2003) regarding recovery, along with those of the Surgeon General's Report on Mental Health (US Department of Health and Human Services 1999), have been instrumental in emphasizing that all mental health care should be consumer and family driven and that the promotion of recovery should be at the core of all mental health care.

In November of 2004, voters in the state of California passed Proposition 63, now known as the Mental Health Services Act (MHSA; Scheffler and Adams 2005). The MHSA levies a $1 \%$ income tax on adjusted gross incomes over $\$ 1$ million to be used for transformational activities in the State's public mental health system and attempts to expand and transform the existing system with a focus on promoting more recovery-oriented programs. The MHSA specifically states, "Planning for services shall be consistent with the philosophy, principles, and practices of the Recovery Vision for mental health consumers: (1) To promote concepts key to the recovery for individuals who have mental illness: hope, personal empowerment, respect, social connections, self responsibility, and self-determination; (2) To promote consumer-operated services as a way to support recovery; (3) To reflect the cultural, ethnic and racial diversity of mental health consumers; (4) To plan for each consumer's individual needs." (Mental Health Services Act 2004). 
California's public mental health system is highly decentralized, and while the state's Department of Mental Health determines broad policy and funding, actual programs and service delivery are the responsibility of California's 58 counties and can vary considerably by county. Programs and service delivery may be shaped by a number of factors including the demographics of staff and influential stakeholders, organizational culture, leadership, and county department of mental health funding levels (Kimberly and Cook 2008; Corrigan et al. 2002; Corrigan et al. 1998). Transforming a public mental health system such as California's requires great change, necessitating "an upheaval and reorganization of what we know, what we do, and how we go about doing it" (Power 2005). In light of this, we seek to understand how each of the above factors may be associated with such change.

In order to properly understand how these factors influence recovery orientation requires us to consider at least two levels of analysis. The first level is the individual level, the level at which consumers interact with the staff members who provide mental health services. These staff members are embedded within county departments of mental health which also influence the way in which mental health services are delivered, which is the second level of analysis. In other words, a thorough analysis must not only include information on staff characteristics and perceptions, but also include information on county mental health department characteristics, taking into account the level at which each characteristic is measured.

Providing mental health care is very labor-intensive; the workforce absorbs nearly $80 \%$ of mental health expenditures (Power 2005). Human capital is the most valuable resource in the mental health care system. The demographics of staff (and influential stakeholders) may significantly influence a county's orientation towards a recovery approach to care by virtue of their education and experience in the mental health care system. For example, those with higher levels of education may be more familiar with the recovery approach; on the other hand, older individuals (age being a proxy for experience) may be more familiar and comfortable with historic approaches and thus potentially less supportive of the recovery approach.

The organizations in which staff members provide mental health care each have distinctive organizational cultures. Organizational culture is an integral part of the social context, exerting a major impact on any attempted change in the organization. The culture is the system norms and values, including expectations, rewards, or punishments; it is "the way things are done" (Glisson 2007). All practices, processes, and outcomes of the mental health system are affected by the organizational social context. Organizations will support, encourage, and reward behavior that moves the system toward the goal of recovery orientation, or they will hinder these behaviors.

Organizational culture that is less insular and more open to change may also have a higher positive association with a recovery orientation (O'Connell et al. 2005). In a widely used taxonomy of organizational culture that divides organizational culture into four categories this culture is known as adhocracy. The other three categories are clannish, hierarchical, and market-oriented (Cameron and Quinn 2006). None of these cultures is inherently positive or negative. Most organizational cultures are combinations of these four types.

The leadership of the county mental health director is likely to play an important role in the recovery orientation of a county mental health department. Leadership can be measured in terms of both styles and outcomes. Since county departments of mental health are heavily impacted by political considerations, leadership that focuses on outcomes that are satisfying to constituents may be more successful in promoting a recovery orientation.

Finally, the economic resources available to county departments of mental health are also likely to have a positive association with their recovery orientation. The recovery approach is effective, but it can also be resource intensive.

We thus make the following hypotheses. At the individual level we hypothesize, with respect to staff characteristics, that being younger and more highly educated will positively relate to recovery orientation. At the individual level we also hypothesize that perceptions that a department's organizational culture is more innovative will positively relate to recovery orientation. At the county level we hypothesize that leadership that is more focused on satisfying outcomes will positively relate to recovery orientation and that larger county mental health budgets will also positively relate to recovery orientation.

\section{Methods}

Sample

Twelve California counties were selected using purposive sampling methods. Our principles for choosing counties stated that the sample should include: (1) counties with populations above 500,000 and those with populations below 500,000, (2) counties from both Northern and Southern California, ${ }^{1}$ (3) counties in the interior and along

\footnotetext{
${ }^{1}$ Note that at least two definitions of the boundary between Northern and Southern California are in use: (1) the Tehachapi mountain range, and (2) the sixth standard parallel south of Mount Diablo. In this paper we use the latter definition. The counties assigned to each part of California will differ slightly depending on which definition is used.
} 
the coast, and (4) rural county representation. The final sample met these criteria. No county asked to participate refused and the sample of counties represented $63 \%$ of the total state population. Urban counties in Northern California included the following (where population is listed in parentheses): Alameda $(1,512,062)$, Fresno $(905,800)$, Monterey $(421,071)$, San Joaquin $(670,159)$, San Francisco $(817,154)$, and San Mateo $(724,945)$. Urban counties in Southern California included Kern $(789,655)$, Los Angeles $(10,232,453)$, Riverside $(2,001,641)$, San Bernardino $(2,009,787)$, and San Diego $(3,076,068)$. We also included a rural county in Northern California: Placer $(322,680){ }^{2}$ Coastal counties included Alameda, Los Angeles, Monterey, San Diego, San Francisco, and San Mateo. Interior counties include Fresno, Kern, Placer, Riverside, San Bernardino, and San Joaquin. All population figures are from 2006 (State of California Department of Finance 2008).

Within each county department of mental health, a coordinator was provided a list of 26 positions (see Table 1) and was asked to provide us with contact information for more than one person (where possible) for each position. Our study team then directly contacted and arranged for interviews (in virtually all cases). ${ }^{3}$ The purpose of the list of positions was to ensure that our potential interviewees represented, as closely as possible, the full range of positions in county departments of mental health. We were able to interview individuals from almost all of the positions listed in Table 1 in almost every county. The final sample consisted of 307 interviews: an average of 25 interviewees per county (range: 17-34). Each person was interviewed for approximately one hour using a semistructured set of interview questions and was also asked to fill out a simple demographic survey and two formal instruments: the Recovery Self Assessment (O'Connell et al. 2005) and the Organizational Culture Assessment Instrument (Cameron and Quinn 2006). A subset of the Multifactor Leadership Questionnaire (MLQ) was given to county mental health directors. Due to incomplete data on some of the measures collected, our sample was reduced to 163 usable observations, or an average of 13.6 interviews per county. Data was collected from November 2006 to April 2007. This study was approved by the Committee for

\footnotetext{
${ }^{2}$ We used membership in the Regional Council of Rural Counties to determine the rural status of a county.

${ }^{3}$ In one county, the coordinator also set up the interviews. In this county we communicated to the coordinator that only those who wished to participate should be included in the interview schedule. We received confirmation back from the coordinator that a number of people did not want to participate and so were not included.
}

Table 1 Purposive sampling: list of potential interviewees

Director

Medical director

CSS plan consultant

MH Dept Staff-cultural competency expert

MH Dept Staff—quality improvement expert

MH Dept Staff — consumer affairs position or patients rights advocate

MH Dept Staff—clinician (involved in the MHSA planning process)

MH Dept Staff-clinician (NOT involved in the MHSA planning process)

MH Dept Staff-manager (involved in the MHSA planning process)

MH Dept Staff-manager (NOT involved in the MHSA planning process)

MH Dept Staff-case manager transitioning to FSP (or involved in the MHSA planning process)

MH Dept Staff-case manager non-FSP (or NOT involved in the MHSA planning process)

MH Dept Staff-homeless coordinator or housing coordinator

MH Dept Staff-individual involved in CSS Planning

MH Dept Staff_-dual diagnosis expert

MH Dept Staff-staff

MH Dept Staff-finance manager

MH Dept Staff—data analyst

NAMI and/or CNMHC representative

UACC Rep

Contracted Provider-clinician

Contracted Provider-manager

Contracted Provider-MH staff

Local mental health board president/representative

Member of the board of supervisors

Union representative

CSS, Community Services and Supports; MH, Mental Health; MHSA, Mental Health Services Act; FSP, Full Service Partnership; NAMI, National Alliance on Mental Illness; CNMHC, California Network of Mental Health Clients; UACC, United Advocates for Children of California

the Protection of Human Subjects at the University of California at Berkeley.

Measures

\section{Demographic Characteristics}

Information on age, gender, race/ethnicity, and education was collected from all of our interviewees. These demographic measures allow us to control for the composition of the mental health staff in each county department of mental health. In particular, the age of mental health practitioners has been shown to be positively correlated with a recovery orientation (McLoughlin and Fitzpatrick 2008). However, McLoughlin and Fitzpatrick (2008) did not attempt to 
determine if a non-linear relationship between age and recovery orientation existed (as we do below).

\section{Recovery and Organizational Culture}

The Recovery Self Assessment (RSA) is a 36-item instrument that was developed to measure "the degree to which programs implement recovery-oriented practices" (O'Connell et al. 2005). Respondents were asked the degree to which various items reflected the activities, values, and practices of their county mental health department. Factor analysis yields five factors in the RSA: (1) life goals (the extent to which staff help with the development and pursuit of the individually-defined life goals of consumers such as employment and education), (2) consumer involvement and education (the extent to which consumers are involved in the development and provision of programs/services, staff training, advisory board/management meetings, and community education activities), (3) diversity of treatment options (the extent to which an agency provides linkages to peer mentors/support, a variety of treatment options, and assistance with becoming involved in non-mental health/addiction activities), (4) rights and respect (the extent to which staff refrain from using coercive measures, provide consumers with access to treatment records, and facilitate outside referrals), and (5) individually-tailored services (the extent to which services are tailored to individual needs, cultures, and interests, provided in a natural environment, and focus on building community connections; O'Connell et al. 2005). The RSA exhibits good internal consistency, test-retest reliability, and it's convergent and discriminant validity are considered adequate (Salyers et al. 2007).

Respondents answer each RSA question using a 5-point Likert scale ( $1=$ strongly disagree to $5=$ strongly agree, not apply) where "not apply" is a valid answer and is counted as zero. The overall score is calculated by summing the points assigned to each question and dividing by the total number of questions. The final score thus ranges from 1 to 5 .

The Organizational Culture Assessment Instrument (OCAI) is based on the Competing Values Framework (Cameron and Freeman 1991) and is comprised of 24 items. It takes a typological approach characterizing organizational culture to the degree to which it is clannish, adhocratic, hierarchical, or market-oriented (Cameron and Quinn 2006). Each culture has positive features. The following descriptions are based on Cameron and Quinn (2006).

Clan culture incorporates the idea that people can be managed most effectively through teamwork and employee development. Clients are considered partners. The organization with this culture strives to empower its staff and develop their participation, commitment, and loyalty.

Adhocratic culture emphasizes innovation and initiative. An organization with this culture attempts to foster creativity, entrepreneurship and values being on the leading edge of a given field.

Market culture refers to organizational culture that is focused on the external environment. Such an organization emphasizes transactions with customers, suppliers, contractors, unions, regulators, etc. Market mechanisms (monetary exchanges) govern its internal working.

Hierarchical culture emphasizes being stable and efficient. It entails clear lines of authority, standardized procedures, and formal control and accountability.

Respondents to the OCAI are presented with 24 items, each of which includes four statements. Respondents are asked to allocate 100 points across the four statements to the extent that each statement describes their organization as it currently exists and are also asked to allocate 100 points across the four statements to the extend that each describes their organization as they would prefer it to be. Each of the cultural types is then scored by summing the number of points respondents have attached to statements applicable to a given type and dividing by the number of statements summed. Each score can thus range from 0 to 100. In order to determine the degree to which organizations are not as staff prefer them to be, we subtract the current measure from the preferred measure. Thus, the final measure can range from -100 to 100 . For example, if the preferred level of adhocracy is 0 and the current level of adhocracy is 100 , then the difference score would be -100 $(0-100=-100)$. Alternative, if the preferred level of adhocracy is 100 and the current level of adhocracy is 0 , then the difference score would be $100(100-0=100)$. Every other set of numbers would fall in between these two extremes.

The OCAI has been used extensively to study organizational culture. There is evidence that the OCAI is reliable and valid (Cameron and Quinn 2006; Goodman et al. 2001; Shortell et al. 1995). The OCAI has also been demonstrated to be associated with relevant outcomes in health care. (Goodman et al. 2001; Scott et al. 2003 Shortell et al. 1995).

\section{Multifactor Leadership Questionnaire}

A subset of the Multifactor Leadership Questionnaire (MLQ) was used to measure the transformational leadership styles and transformational leadership outcomes of county mental health directors. A subset of 29 of the 45 measures of leadership was used to measure Transformational Leadership. Transformational Leadership measures 
how well leaders are able to motivate others to view themselves and their environment differently and influence them about what is important. Within the overall measure of Transformational Leadership are five style subscales and three outcome subscales. The five style subscales are as follows: idealized influence (attributed), idealized influence (behavior), inspirational motivation, intellectual stimulation, and individual consideration. The three outcome subscales are as follows: satisfaction with the leader, effectiveness of the leader, and the extra effort a leader brings forth (Avolio and Bass 2004).

Idealized influence, both attributed and behavior, measures how much leaders instill pride, increase optimism, are trusted, respected, and are seen as charismatic. Inspirational motivation measures a leader's ability to provide meaning to an employee's work, create a challenging environment, communicate a vision and increase subordinate identification with that vision. Intellectual stimulation measures a leader's ability to develop an employee's effort to be creative and innovative through thinking about old situations in new ways, re-conceiving problems and questioning assumptions. Individual consideration measures a leader's success at mentoring, coaching, and developing individual team members (Avolio and Bass 2004).

Satisfaction measures the extent to which leaders' leadership methods and working style are satisfying to those around the leader. Effectiveness measures a leaders' effectiveness in meeting organizational requirements, leading groups, meeting others' job-related needs, and representing others to individuals in higher positions of authority. Extra effort measures the extent to which leaders are able to get others to do more than expected, to expend more effort, and increase their desire to succeed (Avolio and Bass 2004).

Respondents to the MLQ answer each question using the following scale: $0=$ not at all, $1=$ once in a while, $2=$ sometimes, $3=$ fairly often, $4=$ frequently, if not always. Subscale measures are constructed by summing the points assigned to the set of questions that is relevant to each subscale and dividing by the number of questions summed. Each subscale can thus range from zero to four.

Higher average scores reflect greater embodiment and effectiveness of Transformational style leadership. The MLQ and the transformational leadership style have been linked to positive aspects of performance. The MLQ has been used in nearly 300 research programs, doctoral dissertations and master's theses around the globe in 19952004. It has also been translated into 13 different languages (Avolio and Bass 2004).

Note that while self-rated measures of leadership using the MLQ tend to be inflated relative to subordinate ratings, both self-ratings and subordinate ratings do have predictive power (Bass and Yammarino 1991; Atwater et al. 1998;
Biswas 2009). Thus, self-rating was deemed sufficient for this pilot study.

\section{Economic Resources}

Economic resources available in a county for use in the public mental health system are measured as total mental health budget dollars per capita. The size of the budget for county departments of mental health was determined via a separate survey (Finlayson et al. 2007). To adjust for the varying sizes of counties, we used a per capita measure. A per client measure was not used as such measures do not reflect the total resources available within a county, but rather reflect decisions by a county department of mental health regarding how many consumers they will serve and how resource intensive such services are.

\section{Analytical Approach}

At least part of the variation in the recovery orientation of county departments of mental health is assumed to be explained by the characteristics of the county department of mental health staff and influential stakeholders and the characteristics of the county department of mental health. Each county only contains one county department of mental health; so accordingly, a two-level multilevel model with random intercepts was estimated. The following shows each multilevel random-intercept model (i: level-1 unit, individual staff; $j$ : level-2 unit, county) that we estimate where the first model includes leadership characteristics in terms of outcomes and the second includes leadership characteristics in terms of styles.

1. Recovery orientation where transformational leadership is measured in terms of outcomes:

$\mathrm{RSA} \sim \operatorname{Normal}(\mathrm{XB}, \Omega)$

$$
\begin{aligned}
& \mathrm{RSA}=\beta_{0 i j} \text { cons }+\beta_{1} \text { female }_{i j}+\beta_{2} \text { age35_44 } 4_{i j} \\
& +\beta_{3} \text { age } 45 \_54_{i j}+\beta_{4} \text { age } 55 \_64_{i j}+\beta_{5} \text { age } \text { 65plus } i j \\
& +\beta_{6} \text { masters }_{i j}+\beta_{7} \text { doctoral }_{i j}+\beta_{8} \text { clannish }_{i j} \\
& +\beta_{9} \text { adhocracy }_{i j}+\beta_{10} \text { market }_{i j}+\beta_{11} \text { hierarchy }_{i j} \\
& +\beta_{12} \text { budget }_{j}+\beta_{13} \text { satisfaction }_{j}+\beta_{14} \text { effectiveness }_{j} \\
& +\beta_{15} \text { extra_effort } \\
& \beta_{o i j}=\beta_{o}+u_{o j}+e_{o i j} \\
& {\left[u_{o j}\right] \sim \operatorname{Normal}\left(0, \Omega_{u}\right): \Omega_{u}=\left[\sigma_{u 0}^{2}\right]} \\
& {\left[e_{o i j}\right] \sim \operatorname{Normal}\left(0, \Omega_{e}\right): \Omega_{e}=\left[\sigma_{e 0}^{2}\right] .}
\end{aligned}
$$

2. Recovery orientation where transformational leadership is measured in terms of style: 
$\mathrm{RSA} \sim \operatorname{Normal}(\mathrm{XB}, \Omega)$

$$
\begin{aligned}
& \mathrm{RSA}=\beta_{0 i j} \text { cons }+\beta_{1} \text { female }_{i j}+\beta_{2} \text { age35_44 } 4_{i j} \\
& +\beta_{3} \text { age } 45 \_54_{i j}+\beta_{4} \text { age } 55 \_64_{i j}+\beta_{5} \text { age65plus } i j \\
& +\beta_{6} \text { masters }_{i j}+\beta_{7} \text { doctoral }_{i j}+\beta_{8} \text { clannish }_{i j} \\
& +\beta_{9} \text { adhocracy }_{i j}+\beta_{10} \text { market }_{i j}+\beta_{11} \text { hierarchy }_{i j} \\
& +\beta_{12} \text { budget }_{j}+\beta_{13} \text { ideal_attribute }_{j} \\
& +\beta_{14} \text { ideal_behavior }_{j}+\beta_{15} \text { inspirational }_{j} \\
& +\beta_{16} \text { intellectual }_{j}+\beta_{17} \text { consideration }_{j}
\end{aligned}
$$

$\beta_{o i j}=\beta_{o}+u_{o j}+e_{o i j}$

$\left[u_{o j}\right] \sim \operatorname{Normal}\left(0, \Omega_{u}\right): \Omega_{u}=\left[\sigma_{u 0}^{2}\right]$

$\left[e_{o i j}\right] \sim \operatorname{Normal}\left(0, \Omega_{e}\right): \Omega_{e}=\left[\sigma_{e 0}^{2}\right]$.

At level one are the following variables. The variable female represents the female gender; the variables age35_44, age45_54, age55_64, and age65plus represent age ranges; the variables masters and doctoral represent higher education levels; and the variables clannish, adhocracy, hierarchy, and market represent the difference between the preferred organizational culture and the current organizational culture. At level two are the remaining variables. The variable budget is the per capita mental health budget for county departments of mental health. The variables ideal_attribute, ideal_behavior, inspirational, intellectual, and consideration represent the MLQ leadership style measures; and the variables satisfaction, effectiveness, and extra_effort represent the MLQ leadership outcome measures. The reference group is made up of males, who are under age 35 , and have no graduate degree.

The RSA is distributed normally with a mean of XB (the parameters of the equation), and a variance of $\Omega$. The intercept is random at the both the individual level $i$ and the county level $j$ where $e_{\mathrm{o} i j}$ represents the random error at the individual level and $u_{\mathrm{o} j}$ represents the random error at the county level. More detailed technical aspects of multilevel modeling have been discussed elsewhere (Goldstein 1995; Snijders and Bosker 1993).

The multilevel models are estimated using restricted iterative generalized least squares as iterative generalized least squares may produce biased estimates of the random parameters in small samples (Goldstein 1995). Models were fitted using MLwiN (version 2.02; Rasbash et al. 2005).

\section{Results}

The distribution of the RSA was investigated to determine if any transformation was needed in order to fit the model properly. It was found that the RSA was almost perfectly normally distributed and that transformation was unnecessary.

Table 2 presents descriptive statistics for the data set. Race and ethnicity are not included as approximately onethird of survey respondents did not indicate their race or ethnicity. Because of confidentiality agreements, separate statistics for each of the 12 counties cannot be provided.

Because level two only has seven available degrees of freedom in column one of Table 3, the leadership outcome characteristics in the model were dropped except for satisfaction, which was the most statistically significant (had the highest $t$-statistic). As can be seen in column two of Table 3, omitting the remaining leadership outcome measures results in increased precision but little or no bias to the remaining parameters. Similarly, dropping organizational culture types that were not statistically significant also has little effect on the parameters for the remaining organizational culture type. We therefore focus on the results from columns two through seven of Table 3 below.

Starting at level one, we note that while gender has no measurable relationship with recovery orientation, age does. There is a consistent $U$-shaped relationship with age and both the overall RSA and each subscale of the RSA with the dip in age occurring from age 35 to age 64 with the exception of the subscale consumer involvement and education (which only dips for ages 45-54), the subscale life goals vs. symptom management (which only dips for ages 35-54), and the subscale individually-tailored services (which exhibits no relationship with age). In addition, graduate education, both at the masters' level and the doctoral level is consistently and positively related to the overall RSA and to each of its subscales.

Organizational culture measured at the individual level, specifically the difference between the preferred degree of adhocracy and the current degree of adhocracy is strongly and negatively correlated to both the overall RSA measure and each of its subscales with the notable exception of life goals vs. symptom management. In other words, the further an organization is from an adhocratic culture (where adhocratic culture is preferred), the less recovery oriented it is. Stated positively, this result shows that the closer an organization is to an adhocratic culture (where adhocratic culture is preferred), the more recovery oriented it is.

Moving to level two, we find that with respect to leadership outcomes, satisfaction was positively correlated to the overall RSA measure (column 2: coefficient $=0.550$, standard error $[\mathrm{SE}]=0.229, t$ (degrees of freedom $[d f]=9, P \leq .0 .05)$ and to two subscales: diversity of treatment option (column 3: coefficient $=0.548, \mathrm{SE}=$ $0.218, t(d f=9, P \leq .0 .05$ ), and rights and respect (column 6: coefficient $=0.684, \mathrm{SE}=0.214, t(d f=9, P \leq .0 .05)$. Also at level 2, the total per capita size of the budget of the 
Table 2 Data description

$S D$ standard deviation, Min minimum, Max maximum

\begin{tabular}{|c|c|c|c|c|}
\hline Variable & Mean/proportion & SD & Min & Max \\
\hline \multicolumn{5}{|l|}{ Level one (individual) } \\
\hline \multicolumn{5}{|l|}{ Outcome (means) } \\
\hline RSA (scale 1-5) & 3.05 & 0.70 & 0.33 & 4.56 \\
\hline \multicolumn{5}{|l|}{ Sociodemographics (proportions) } \\
\hline Female & 0.57 & - & 0.00 & 1.00 \\
\hline Ages 35-44 & 0.21 & - & 0.00 & 1.00 \\
\hline Ages 45-54 & 0.42 & - & 0.00 & 1.00 \\
\hline Ages 55-64 & 0.26 & - & 0.00 & 1.00 \\
\hline Ages 65 and older & 0.04 & - & 0.00 & 1.00 \\
\hline Masters & 0.60 & - & 0.00 & 1.00 \\
\hline Doctoral & 0.21 & - & 0.00 & 1.00 \\
\hline \multicolumn{5}{|l|}{ OCAI (means: desired-current) } \\
\hline Clan index (scale -100-100) & 8.01 & 10.30 & -37.50 & 41.67 \\
\hline Adhocracy index (scale $-100-100$ ) & 6.59 & 8.58 & -16.67 & 41.67 \\
\hline Market index (scale -100-100) & -3.75 & 9.21 & -32.50 & 21.67 \\
\hline Hierarchy index (scale $-100-100$ ) & -10.04 & 14.86 & -72.50 & 56.67 \\
\hline \multicolumn{5}{|l|}{ Level two (county) } \\
\hline Mental health budget per capita (\$) & 101.33 & 36.16 & 66.58 & 208.98 \\
\hline \multicolumn{5}{|l|}{ MLQ (means) } \\
\hline Ideal attribute (scale $0-4$ ) & 3.51 & 0.37 & 2.50 & 4.00 \\
\hline Ideal behavior (scale 0-4) & 3.65 & 0.49 & 2.25 & 4.00 \\
\hline Inspirational motivation (scale 0-4) & 3.48 & 0.44 & 2.75 & 4.00 \\
\hline Intellectual stimulation (scale 0-4) & 3.40 & 0.36 & 2.75 & 4.00 \\
\hline Individual consideration (scale $0-4$ ) & 3.34 & 0.30 & 3.00 & 4.00 \\
\hline Satisfaction (scale 0-4) & 3.36 & 0.46 & 2.50 & 4.00 \\
\hline Effectiveness (scale 0-4) & 3.48 & 0.40 & 2.75 & 4.00 \\
\hline Extra effort (scale 0-4) & 3.41 & 0.51 & 2.67 & 4.00 \\
\hline Observations & 163 & & & \\
\hline
\end{tabular}

department of mental health is positively related to the overall RSA (coefficient $=0.007, \mathrm{SE}=0.003, t(d f=9$, $P \leq .0 .05)$ and to two subscales: diversity of treatment options $\quad$ (coefficient $=0.548, \quad \mathrm{SE}=0.218, \quad t(d f=9$, $P \leq .0 .05$ ), and rights and respect (coefficient $=0.684$, $\mathrm{SE}=0.214, t(d f=9, P \leq .0 .05)$.

Model 2 (not shown) was virtually the same as model 1 with respect to level one coefficients but did not show any statistically significant parameters with respect to level two variables. This was true whether the leadership style variables were included as the single overall mean of the MLQ, separated by subscale and included together (five subscales), or separated by subscale with each subscale included in a separate model.

An analysis of the intra-class correlation coefficients (ICC) shows what proportion of the total residual variation is due to differences between county mental health departments. We find that this measure varies from zero to $12.6 \%$ of the total residual variation in recovery orientation being due to differences between county mental health departments.

\section{Discussion}

This pilot study made the following hypotheses regarding recovery orientation in county departments of mental health. At the individual-level we hypothesized that being younger and more highly educated would positively relate to recovery orientation, and that perceptions that a department's organizational culture is more innovative would positively relate to recovery orientation. At the county level we hypothesized that leadership that is more focused on satisfying outcomes will positively relate to recovery orientation, and that larger county mental health budgets will positively relate to recovery orientation. We found strong support for each of these hypotheses with the exception of age, which exhibited a $U$-shaped relationship with recovery orientation.

Graduate education matters a great deal. This is not to say that individuals who have education below the graduate level cannot be trained to be just as recovery-oriented as those with higher levels of education or that all individuals with graduate education are recovery oriented. It rather 


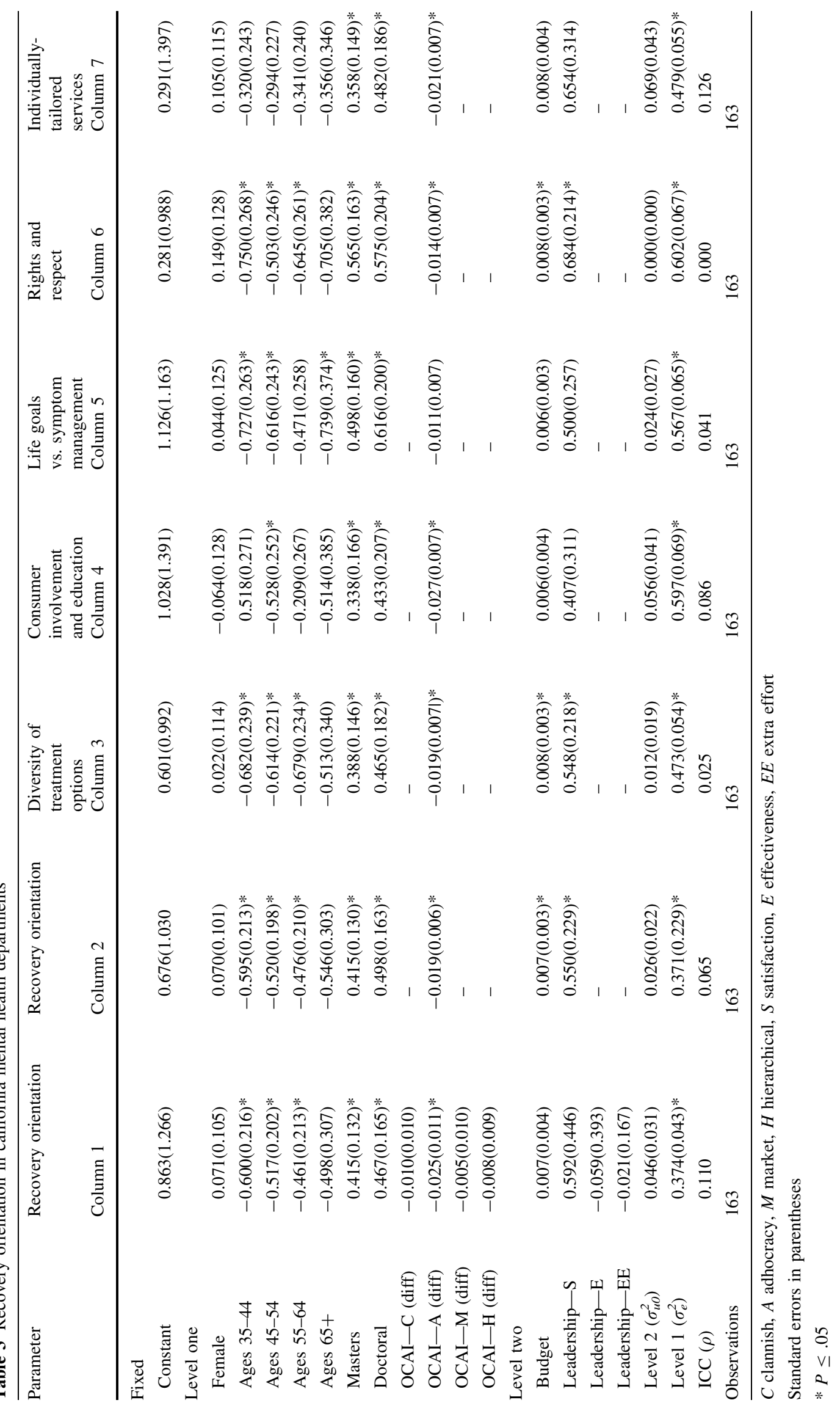


suggests that more intensive training in recovery orientation may be needed for individuals without graduate education.

Organizational culture, specifically adhocratic culture, appears to be a critical factor in either hindering or facilitating a recovery orientation in county mental health departments. The adhocratic culture can more easily incorporate change and fosters innovation. County mental health departments characterized by this culture are thus more likely to be on the leading edge of mental health practice. These findings are consistent with those of Glisson (2007) who found that turnover, work attitudes, service quality, and service outcomes are affected by organizational culture. A positive organizational culture was found to improve all of these measures.

The importance of organizational culture at this time in counties in California cannot be overemphasized. Virtually every county in California will experience change as a result of MHSA. A majority of counties will likely face significant challenges in their efforts to meet MHSA's mandates. Changes in how consumers are engaged and the types of services provided, restructuring of departments, retraining of personnel, hiring of additional staff, inclusion of consumers and consumer's families in care planningall of this and more will be required to fulfill MHSA's dual intent of service expansion and system transformation. Organizations that value innovation and are able to actively and positively manage change will likely be more successful by supporting a change in culture (Huw et al. 2000).

In addition, given the political nature of jobs such as the director of a county department of mental health, the finding that leadership outcomes that focus on satisfying those the director works with comes as no surprise. Directors who can satisfy those around them are able to maintain their positions and thus are more likely to be able to advance a recovery-oriented style of practice.

Fully complementary to the two above findings is the finding that county departments of mental health with larger per capita budgets are more likely to be recovery oriented. This may be due to a number of possible factors; including there being sufficient services and resources to support a broad range of programs and services. Alternatively, larger per capita budgets allow change to take place more quickly. Change is not free. It takes money both to train staff in the recovery orientation and to provide services to consumers in ways consistent with a recovery orientation.

The findings also point towards some specific areas that counties can focus on to improve their recovery orientation. The only subscale of the RSA that adhocratic culture did not positively correlate with is life goals vs. symptom management. Of significance is that this subscale was also a subscale with no correlation with either the size of the budget or the leadership of the director. This suggests that specific training in this area may be warranted.
Similarly, neither budget nor leadership had any association with the RSA subscales consumer involvement and education or individually-tailored services. Again, focused training on these areas of recovery may help to improve this aspect of recovery and result in improving the overall recovery orientation of county departments of mental health. For example, Assertive Community Treatments (ACT) can be implemented with a recovery orientation (Salyers and Tsembris 2007) and recovery-oriented outcome measures can be implemented (Fisher et al. 2009; Miller et al. 2009).

Beyond specific training, organizational culture can be altered and to some extent desired change can be promoted or even directed. Culture change strategies should be selective and designed to balance continuity and change while retaining historically effective aspects of the organization's functions. The culture change within these county organizations must be addressed simultaneously with financing issues related to the implementation of MHSA, accountability to outcomes specified by MHSA legislation, changes in the actual structure of the organization, and human resource management initiatives (Huw et al. 2000).

\section{Limitations}

This pilot study was conducted with a single fiscal year of data. Because it uses cross-sectional data, only associations can be determined from the results; causation cannot be rigorously inferred.

The sample used in each county department of mental health was not randomly selected. While purposive sampling techniques attempted to achieve a representative grouping of individuals to interview, selection bias cannot be ruled out.

In addition, this pilot study only used data on 12 of the 58 counties in California representing $63 \%$ of the population in California. While an attempt at representativeness was made with regard to the inclusion of counties, counties were not selected at random and thus the results of this study may be subject to selection bias. In particular, our sample of counties included only one rural county which may limit the external validity of our findings with respect to rural counties.

Finally, $360^{\circ}$ evaluation was not used in this study to measure leadership characteristics; leaders only rated themselves. As noted above, while such self-ratings are sufficient for pilot studies, future studies should be use complete 360 evaluations using the MLQ.

\section{Conclusion}

The findings of this study strongly suggest that county mental health departments should consider the importance 
of education, organizational culture, leadership outcomes, and economic resources, in structuring their efforts at MHSA implementation and systems transformation. Those with less education can be more intensively trained, organizational culture can become more adhocratic, satisfactory leadership can be cultivated, and economic resources can be increased with creative efforts. Creativity lies at the heart of all of these efforts and is critical for success. There is a large literature on stimulating and enhancing creativity within organizations; application of this knowledge should be part of state and county efforts at improving the lives of consumers (e.g., see Shalley and Gibson 2004).

In addition, routine administration of the MLQ and OCAI in counties should be done to track the direction of their leadership and their organizational culture. These instruments are easy to administer, take only minutes to complete, and inexpensive web-based survey services can automatically distribute the instruments and make the resulting data available in a ready-to-analyze format to county analysts and decision makers. By tracking such measures before and after initiatives designed to engage in organizational change, counties can inexpensively determine the relative success of their efforts.

The above research was conducted either just before or right at the beginning of the implementation of the MHSA for each of the counties included in this study. A second series of data should be collected, along with information on the types and amounts of recovery-oriented training that were conducted in each county to determine the effectiveness of such training. The information from an analysis of such information would be extremely valuable for counties across California and the nation.

Acknowledgments This research was funded by the California Healthcare Foundation (Award \#04-1616). The authors would like to acknowledge Tracy Finlayson for identifying the survey instruments and Bonnie Li for entering data.

Open Access This article is distributed under the terms of the Creative Commons Attribution Noncommercial License which permits any noncommercial use, distribution, and reproduction in any medium, provided the original author(s) and source are credited.

\section{References}

Atwater, L. E., Ostroff, C., Yammarino, F. J., \& Fleenor, J. W. (1998). Self-other agreement: does it really matter? Personnel Psychology, 51, 577-598.

Avolio, B. J., \& Bass, B. M. (2004). Multifactor leadership questionnaire, third edition, manual and sample set; Mind Garden, Inc.; 2004.

Bass, B. M., \& Yammarino, F. J. (1991). Congruence of self and others' leadership ratings of naval officers for understanding successful performance. Applied Psychology: An International Review, 40, 437-454.
Biswas, S. (2009). HR practices as a mediator between organizational culture and transformational leadership: implications for employee performance. Psychological Studies, 54, 114-123.

Cameron, K. S., \& Freeman, S. J. (1991). Cultural congruence, strength, and type: Relationships to effectiveness. Research in Organizational Change and Development, 5, 23-58.

Cameron, K. S., \& Quinn, R. E. (2006). Diagnosing and changing organizational culture. San Francisco, CA: Jossey-Bass.

Corrigan, P. W., Diwan, S., Campion, J., \& Rashid, F. (2002). Transformational leadership and the mental health team. Administration and Policy In Mental Health, 30, 97-108.

Corrigan, P. W., Garman, A. N., Lam, C., \& Leary, M. (1998). What mental health teams want in their leaders. Administration and Policy In Mental Health, 26, 111-123.

Farkas, M., Gagne, C., Anthony, W., \& Chamberlin, J. (2005). Implementing recovery oriented evidence based programs: Identifying the critical dimensions. Community Mental Health Journal, 41, 141-158.

Finlayson, T. L., Adams, N., Rice, J., Felton, M., Brown, T. T., \& Scheffler, R. M. (2007). California on the Eve of mental health reform. Baseline report on county mental health departments' structure, financing and expenditures, Fiscal Year 2003-2004: One Year Prior to The Mental Health Services Act. The Nicholas C. Petris Center on Health Care Markets and Consumer Welfare, Berkeley: University of California.

Fisher, D. G., Pilon, D., Hershberger, S. L., Reynolds, G. L., LaMaster, S. C., \& Davis, M. (2009). Psychometric properties of an assessment for mental health recovery programs, Community Mental Health Journal, 45, 246-250.

Glisson, C. (2007). Assessing and changing organizational culture and climate for effective services. Research on Social Work Practice, $17,736$.

Goldstein, H. (1995). Multilevel statistical models (2nd ed.). London: Edward Arnold.

Goodman, E., Zammuto, R., \& Gifford, B. (2001). The competing values framework: Understanding the impact of organizational culture on the quality of work life. Organizational Development Journal, 19, 58-68.

Harding, C. M. (2004). Overcoming the persistent resistance of clinicians to ideas of recovery in serious mental illness. In P. Ridgway \& P. Deegan (Eds.), Deepening the mental health recovery paradigm: Defining implications for practice. Lawrence, KA: University of Kansas Press.

Harding, C. M., Brooks, G. W., Ashikaga, T., Strauss, J. S., \& Breier, A. (1987). The Vermont longitudinal study of persons with severe mental illness, I: Methodology, study sample, and overall status 32 years later. American Journal of Psychiatry, 144, 718726.

Huw, T., Davies, O., Nutley, S., \& Mannion, R. (2000). Organisational culture and quality of health care. Quality in Health Care, 9, 111-119.

Kimberly, J., \& Cook, J. (2008). Organizational measurement and the implementation of innovations in mental health services. Administration and Policy In Mental Health, 35, 11-20.

McLoughlin, K. A., \& Fitzpatrick, J. J. (2008). Self-reports of recovery-oriented practices of mental health nurses in state mental health institutes: Development of a measure. Issues in Mental Health Nursing, 29(10), 1051-1065.

Mental Health Services Act. (2004). California department of mental health. Accessed September 25, 2009. http://www.dmh.ca.gov/ prop_63/MHSA/docs/Mental_Health_Services_Act_Full_Text. pdf.

Miller, L., Brown, T. T., Pilon, D., Scheffler, R. M. \& Davis, M. (2009). Patterns of recovery from severe mental illness: a pilot study. Community Mental Health Journal. doi:10.1007/s10597009-9211-x. 
New Freedom Commission on Mental Health. (2003). Achieving the promise: Transforming mental health care in America, final report (DHHS Pub. No. SMA-03-3832). Rockville, MD: US Department of Health and Human Services.

O’Connell, M., Tondora, J., Croog, G., Evans, A., \& Davidson, L. (2005). From rhetoric to routine: Assessing perceptions of recovery-oriented practices in a state mental health and addiction system. Psychiatric Rehabilitation Journal, 28, 378-386.

Power, A. K. (2005). Achieving the promise through workforce transformation: a view from the center for mental health services. Administration and Policy In Mental Health, 32, 489-495.

Rasbash, J., Steele, F., Browne, W., \& Prosser, B. (2005). A user's guide to MLwiN, version 2.0. Bristol: Center for Multilevel Modeling, University of Bristol.

Salyers, M. P., Tsai, J., \& Stultz, T. A. (2007). Measuring recovery orientation in a hospital setting. Psychiatric Rehabilitation Journal, 31, 131-137.

Salyers, M. P., \& Tsembris, S. (2007). Act and recovery: Integrating evidence-based practice and recovery orientation on assertive community treatment teams. Community Mental Health Journal, 43(6), 619-641.

Scheffler, R., \& Adams, N. (2005). Millionaires and mental health: Proposition 63 in California. Health Affairs, 25, 212-224.

Scott, T., Mannion, R., Marshall, M., \& Davies, H. (2003). Does organizational culture influence health care performance? Journal of Health Services Research Policy, 8, 105-117.
Shalley, C. E., \& Gibson, L. L. (2004). What leaders need to know: A review of social and contextual factors that can foster or hinder creativity. The Leadership Quarterly, 15(1), 33-53.

Shortell, S. M., O’Brien, J. L., Carman, J. M., Foster, R. W., Hughes, E. F., Boerstler, H., et al. (1995). Assessing the impact of continuous quality improvement/total quality management: concept versus implementation. Health Services Research, 30, 377-401.

Snijders, T. A. B., \& Bosker, R. J. (1993). Standard errors and sample sizes for two-level research. Journal of Educational and Behavioral Statistics, 18, 237-259.

Sowers, W. (2005). Quality management committee of the american association of community psychiatrists. Transforming systems of care: The American association of community Psychiatrists guidelines for recovery oriented services. Community Mental Health Journal, 41, 757-774.

State of California, Department of Finance (2008). California county population estimates and components of change by year, July 1 , 2000-2008. Sacramento, California.

US Department of Health and Human Services. (1999). Mental health: A report of the surgeon general-Executive summary. Rockville, MD: US Department of Health and Human Services, Substance Abuse and Mental Health Services Administration, Center for Mental Health Services, National Institutes of Health, National Institute of Mental Health. 